Ciência Florestal, Santa Maria, v. 20, n. 3, p. 467-476 jul.-set., 2010

\title{
RELAÇÃO DE VARIÁVEIS METEOROLÓGICAS COM O CRESCIMENTO DAS ÁRVORES DE Araucaria angustifolia (Bertol.) Kuntze EM POVOAMENTOS IMPLANTADOS
}

\section{RELATIONSHIP OF METEOROLOGICAL VARIABLES WITH THE GROWTH OF Araucaria angustifolia (Bertol.) Kuntze TREES IN IMPLANTED STANDS}

\author{
Magda Lea Bolzan Zanon ${ }^{1}$ César Augusto Guimarães Finger ${ }^{2}$
}

\section{RESUMO}

Este trabalho foi realizado na Floresta Nacional de São Francisco de Paula, RS, e teve como objetivo avaliar a periodicidade do crescimento das árvores de Araucaria angustifolia, correlacionando-a com variáveis meteorológicas. O comportamento do crescimento foi obtido partindo do acompanhamento quinzenal de periodicidade por meio da instalação de cintas dendrométricas à altura do peito de 48 árvores femininas e 48 árvores masculinas, avaliadas durante o período de agosto de 2003 a agosto de 2006. Os resultados deste trabalho permitiram concluir que o início do crescimento anual em diâmetro das árvores ocorre em setembro, tendo seu pico no mês de janeiro, começando a decrescer a partir de março. As variáveis meteorológicas, como temperatura e precipitação, estão diretamente correlacionadas com o incremento. $\mathrm{O}$ aumento da temperatura e da precipitação influi positivamente no incremento e a ocorrência de precipitação acompanhada de temperaturas baixas reduz o crescimento em diâmetro.

Palavras-chave: incremento; diâmetro; cintas dendrométricas; fatores climáticos.

\begin{abstract}
This study was conducted at São Francisco de Paula National Forest, in the state of RS, Brazil, and had as its objective the evaluation of the periodicity growth of Araucaria angustifolia trees, and correlation with meteorological variables. Growth was measured biweekly in 48 female trees and 48 male trees using dendrometric bands installed at breast height. The results allowed us to conclude that the trees' annual growth in DBH starts in September, reaching its peak in January and starting to decrease in March, being almost null after the third week of April. Meteorological variables, such temperature and precipitation, were directly correlated with the increment. The increase in temperature and precipitation positively influence the increment and precipitation followed by low temperatures reduce growth in diameter.
\end{abstract}

Keywords: Increment; diameter; dendrometric bands; climatic factors.

\section{INTRODUÇÃO}

O crescimento de uma árvore é definido como o aumento gradativo de tamanho de raízes, copa e tronco, em resposta aos processos naturais de vida e aos estímulos ambientais (HUSCH et al., 1982).

$\mathrm{O}$ crescimento de árvores depende de fatores como a disponibilidade dos recursos ambientais (temperatura, precipitação, vento, insolação e nutrientes), espaços físicos, edáficos (características físicas, químicas e biológicas), topográficos (inclinação, altitude e exposição) e fatores de competição pela influência de outras espécies, tamanho e constituição genética da árvore bem como sua história de desenvolvimento. Cada um destes pode afetar de forma isolada ou em conjunto o crescimento das árvores (POORTER e BONGERS, 1993).

O desenvolvimento radial ou diamétrico

1. Engenheira Florestal, Dra ${ }^{\mathrm{a}}$, Professora Adjunta do Departamento de Engenharia Florestal, Centro de Educação Superior Norte, Universidade Federal de Santa Maria, Linha Sete de Setembro s/n, BR 386, Km 40, CEP 98400-000, Frederico Westphalen, (RS).magdazanon@smail.ufsm.br.

2. Engenheiro Florestal, Dr., Professor Associado do Departamento de Ciências Florestais, Centro de Ciências Rurais, Universidade Federal de Santa Maria, Av. Roraima, 1000, CEP 97105-9000, Santa Maria (RS). finger@smail.ufsm.br

Recebido para publicação em 12/03/2009 e aceito em 28/01/2010. 
varia significativamente entre e dentro das espécies arbóreas e de acordo com a idade, estações do ano e condições microclimáticas (HIGUSHI et al., 2003).

Pesquisas têm demonstrado que muitas espécies florestais tropicais e subtropicais apresentam crescimento intermitente, em resposta às condições ambientais, afetando frequentemente os inúmeros processos fisiológicos das árvores com reflexo sobre a atividade cambial.

$\mathrm{O}$ excesso ou insuficiência de água disponível no solo causa um decréscimo na taxa fotossintética refletindo na diminuição do crescimento das plantas.

Jacoby (1989) relata que as variações de temperatura, precipitação, radiação solar, entre outros elementos meteorológicos, são mais significativos em áreas de clima temperado do que em climas tropicais, quando discutido o ritmo de crescimento das árvores. Contudo, estudos de fenologia têm demonstrado uma nítida periodicidade desses eventos na produção e queda das folhas, frutificação e floração, induzidos por elementos meteorológicos refletindo na atividade cambial e na formação de anéis de crescimento.

A influência da temperatura e precipitação sobre a distribuição e o crescimento das florestas é demonstrada pela alta correlação existente entre esses aspectos e as classificações climáticas, como as feitas por Merriam, Köppen e Thornthwaite (SPURR e BARNES, 1973).

Em estudo realizado nas montanhas do Colorado nos Estados Unidos, objetivando avaliar a taxa de crescimento do tronco de árvores, Villalba e Weblen (1994) verificaram que indivíduos localizados em áreas mais secas tinham maior correlação entre a atividade cambial e as variações meteorológicas do que aqueles indivíduos localizados em lugares com maior umidade. Comprovando as relações existentes entre vigor e desenvolvimento de uma árvore ou espécie, e condições meteorológicas, como temperatura e umidade, e condições edáficas.

Worbes (1995) também estudou a influência das flutuações climáticas sobre o crescimento de 37 espécies florestais localizadas na Reserva Florestal de Caparaó, na Venezuela. Observou que a atividade cambial foi mais alta no período das chuvas decrescendo no período seco até a dormência cambial.

A variabilidade no regime hídrico pode acarretar alterações nas taxas de crescimento arbóreo (CLARK e CLARK, 1994; VETTER e BOTOSSO,
1989), uma vez que a precipitação é a maior fonte de umidade do solo e, consequentemente, a principal fonte de água para a vegetação.

Ishii (2000) avaliou durante dois anos os ritmos de crescimento de espécies do pantanal como Genipa americana, Inga vera ssp affinis, Tabebuia aurea, Tabebuia heptaphylla e Vochysia divergens, e observou que o crescimento era relacionado com a sazonalidade das chuvas, não havendo crescimento no período de seca e crescimento limitado nas estações de inundações, quando as espécies ficavam por um longo tempo com solo coberto por água, o que causava estresse hídrico nas plantas.

$\mathrm{O}$ mesmo fato foi observado por Teixeira (2000) quando estudou três árvores de Crataeva tapia, espécie frequente na mata ciliar do rio Paraguai, sendo uma espécie adaptada às áreas inundáveis, passando grande parte do tempo em solo alagado. Verificou que o crescimento em diâmetro dos indivíduos estudados foi pequeno, não havendo grandes diferenças entre o início e final do experimento. $\mathrm{O}$ crescimento ocorreu em especial, no período em que não houve precipitações elevadas, sugerindo que, para espécie Crataeva tapia, a dormência cambial pode ser causada pela inundação como ocorre em algumas espécies das áreas inundadas da Amazônia Central.

Este trabalho tem por objetivo identificar a influência dos elementos meteorológicos no crescimento da Araucaria angustifolia em floresta implantada.

\section{MATERIAL E MÉTODO}

\section{Caracterização do local}

O estudo foi realizado na Floresta Nacional (FLONA) de São Francisco de Paula, localizada no Rincão dos Kröeff no município de São Francisco de Paula, RS, a $27 \mathrm{~km}$ da sede do Município. Entre as coordenadas $29^{\circ} 23^{\prime}$ e $29^{\circ} 27^{\prime}$ de latitude Sul e $50^{\circ} 23^{\prime}$ e $50^{\circ} 25^{\prime}$ de longitude Oeste, na Serra Gaúcha, região nordeste, microrregião dos Campos de Cima da Serra, na borda do Planalto, zona de transição entre Floresta Ombrófila Densa e Floresta Ombrófila Mista.

A Floresta Nacional de São Francisco de Paula situa-se a $930 \mathrm{~m}$ acima do nível do mar e apresenta uma área total de 1.606,69 hectares, sendo 901,9 ha de florestas nativas $(56,1 \%), 476,9$ ha de florestas plantadas $(29,7 \%)$ e 227,9 ha sem cobertura florestal (IBAMA 2000). 
A área plantada com Araucaria angustifolia é de 321,3 ha ocupando $20,0 \%$ do total da FLONA. A temperatura média anual é de $14,5^{\circ} \mathrm{C}$, a média das máximas do mês mais quente é de $20^{\circ} \mathrm{C}$ e a do mês mais frio é de $5,7^{\circ} \mathrm{C}$; a máxima absoluta é de $34^{\circ} \mathrm{C}$ e a mínima absoluta é de $-6,5^{\circ} \mathrm{C}$. Temperaturas negativas podem ocorrer durante os meses de abril a novembro (BACKES e IRGANG, 2002).

O clima da área de estudo, de acordo com a classificação de Köppen, é do tipo "Cfb", mesotérmico médio (MORENO, 1961). Esse clima domina as cotas altimétricas entre 1.000 e $1.100 \mathrm{~m}$ no nordeste do Rio Grande do Sul.

\section{Dados meteorológicos}

Os dados meteorológicos para este estudo foram obtidos no 8o Distrito de Meteorologia, DISME/INMET com sede em Porto Alegre, RS. Os dados utilizados são provenientes da estação meteorológica de Cambará do Sul, distante $48 \mathrm{~km}$ da área de estudo. A estação de Cambará do Sul se encontra a $905 \mathrm{~m}$ de altitude, sendo as condições da estação com disponibilidade de dados que mais se aproximam das condições da área em estudo.

Os dados como temperatura mensal, temperatura média das máximas, temperatura média das mínimas, temperatura extrema máxima, temperatura extrema mínima, umidade relativa do ar, precipitação, evaporação mensal, velocidade do vento e número de geadas mensais foram analisados no período de agosto de 2003 a julho de 2006.

Para o cálculo da Evapotranspiração Potencial(ETP), segundo o método de Thornthwaite, são necessárias, como dados básicos, as temperaturas e as precipitações mensais (THORNTHWAITE e MATHER, 1957). equações:

Para tanto, foram usadas as seguintes

$$
\begin{gathered}
E T P=E T P_{N} \times F C \\
E T P_{N}=16 \times\left(\frac{10 * T}{I}\right)
\end{gathered}
$$

Em que: ETP = evapotranspiração potencial mensal, $\mathrm{mm} ; \mathrm{ETP}_{\mathrm{N}}=$ evapotranspiração potencial mensal não ajustada, $\mathrm{mm} ; \mathrm{T}=$ temperatura média mensal, ${ }^{\circ} \mathrm{C}$; I = índice de calor anual (soma dos 12 índices mensais de calor ' $i$ '): $\mathrm{i}=$ índice mensal de calor dado por:

$$
i=\left(\frac{T}{5}\right)^{1,514}
$$

$\mathrm{a}=$ função cúbica do índice I, obtida pelo desenvolvimento em série do 'I':

0,492 ;

$$
\mathrm{a}=6,75 \cdot 10^{-7} \cdot \mathrm{I}^{3}-7,71 \cdot 10^{-5} \cdot \mathrm{I}^{2}+1,79 \cdot 10^{-2} \cdot \mathrm{I}+
$$

$\mathrm{FC}=$ fator de correção (função do comprimento do dia médio do mês $(\mathrm{N})$ e do número (n) de dias do mês, dado por:

$$
F C=\left(\frac{n}{30}\right) *\left(\frac{N}{12}\right)
$$

\section{Seleção de árvores amostras}

Para o estudo do crescimento em diâmetro, foram selecionadas 96 árvores-amostras de Araucaria angustifólia, sendo 48 árvores do sexo feminino e 48 árvores do sexo masculino. Foram confeccionadas cintas dendrométricas permanentes as quais foram instaladas, em cada uma das árvores, para posterior avaliação do crescimento dos indivíduos. As cintas foram colocadas na posição do DAP.

Os levantamentos foram efetuados quinzenalmente partindo da instalação do aparelho, sendo desprezadas as medições efetuadas nos dois primeiros meses em razão do tempo de ajuste e acomodação das cintas dendrométricas. As medições foram realizadas durante 3 anos propiciando assim a análise quinzenal, mensal e anual do crescimento diamétrico das árvores.

\section{RESULTADOS E DISCUSSÃO}

\section{Análise dos fatores climáticos}

Fenômenos meteorológicos como precipitação, temperatura e luz afetam o desenvolvimento das árvores. $\mathrm{O}$ efeito desses fatores no controle da periodicidade do câmbio tem sido observado por diversos autores. Waisel e Fahn (apud CARDOSO, 1991), relatam que a temperatura é considerada um dos principais fatores para a avaliação do câmbio que, juntamente com o fotoperíodo, comanda a formação do tipo de madeira, quando nos dias longos é produzido lenho 
primaveril e nos curtos lenho outonal.

Os resultados apontados nas Figuras 1 e 2 representam os dados de precipitação, temperatura média mensal, e evapotranspiração potencial para todo o período de avaliação. Analisando a Figura 1, observa-se que, no primeiro período de avaliação, (agosto de 2003 a julho de 2004), o máximo valor de precipitação foi de 235,8 $\mathrm{mm}$ no mês de março, e a máxima temperatura média de $18,3^{\circ} \mathrm{C}$, no mês de janeiro, sendo o valor mais baixo de precipitação média mensal registrado em agosto de 2003, com $47,7 \mathrm{~mm}$, e a mínima temperatura média foi também no mês de agosto com $10,1^{\circ} \mathrm{C}$ seguido do mês de maio e julho de 2004 com $10,9^{\circ} \mathrm{C}$ e9, $6^{\circ} \mathrm{C}$ respectivamente.

No segundo período avaliado (agosto de 2004 a julho de 2005), a máxima precipitação ocorreu no mês de setembro com $248 \mathrm{~mm}$ e a máxima temperatura média foi de $19,3^{\circ} \mathrm{C}$, também no mês de janeiro, sendo o menor valor de precipitação registrado no mês de agosto de 2004 com 40,2 mm, e a menor temperatura registrada em julho de 2005 , com $10,3^{\circ} \mathrm{C}$. No último período de análise (agosto de 2005 a julho de 2006), a maior precipitação ocorreu no mês de agosto com 306,7 $\mathrm{mm}$, seguido de outubro com $271,1 \mathrm{~mm}$. Nesse período, a temperatura média máxima ocorreu no mês de janeiro com $19,8^{\circ} \mathrm{C}$, os menores valores de precipitação e temperatura foram registrados nos meses de julho de 2006 e setembro de 2005 com $69,4 \mathrm{~mm}$ e $10,4^{\circ} \mathrm{C}$ respectivamente.

$\mathrm{Na}$ Figura 2, pode-se observar que os maiores valores de evapotranspiração potencial mensal (ETP) ocorreram nos meses de outubro de 2003, seguido de março e maio de 2004 no primeiro período de avaliação (agosto de 2003 a julho de 2004). Nesse primeiro período de avaliação, ocorreu menor déficit hídrico do que no período de agosto de 2004 a julho de 2005.

À medida que o solo vai secando durante os períodos de menor pluviosidade da estação de crescimento, todos os processos fisiológicos vão se restringindo. Dessa forma, em consequência da falta de água no solo, existem períodos de menor crescimento vegetativo correlacionados com menores volumes de precipitação.

No segundo período (agosto de 2004 a julho de 2005), os maiores valores de evapotranspiração foram observados nos meses de setembro de 2004, seguido de maio e julho de 2005, ocorrendo déficits hídricos nos meses de dezembro, janeiro e fevereiro. No terceiro período de avaliação, que compreendia de agosto de 2005 a julho de 2006, ocorreram os maiores valores de evapotranspiração entre os três anos analisados (agosto, setembro, outubro de 2005 e maio de 2006), período esse caracterizado pelo excesso hídrico. Os meses de dezembro, fevereiro, abril e julho também apresentaram déficit hídrico.

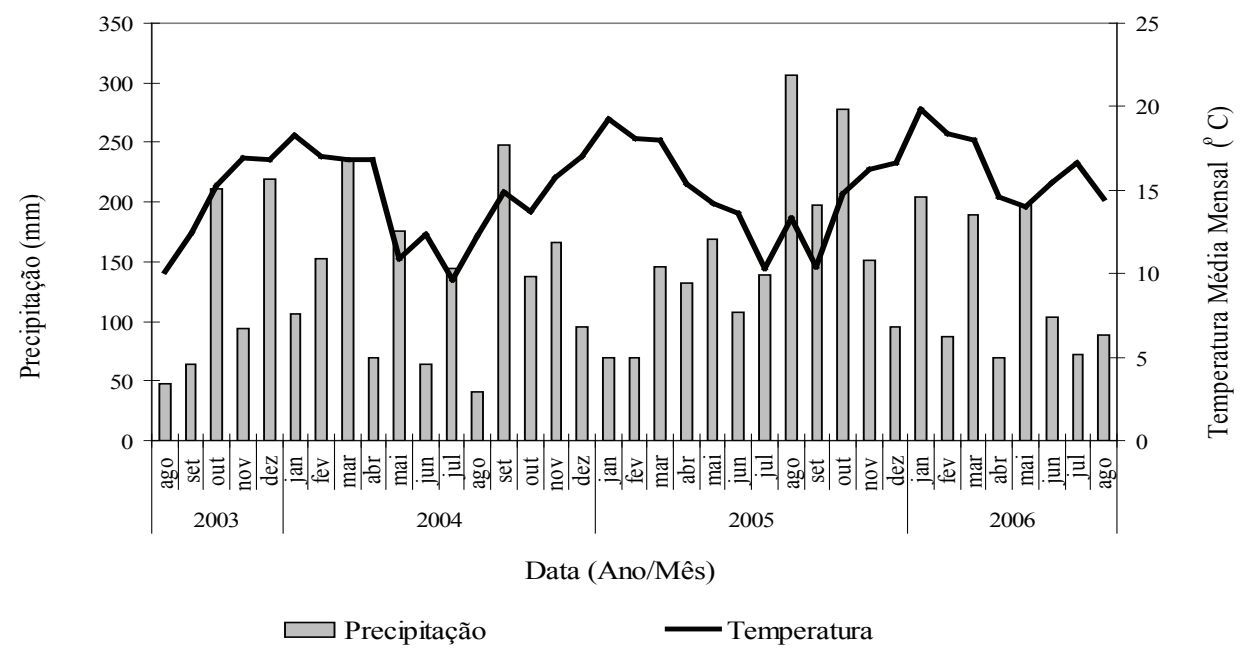

FIGURA 1: Precipitação e temperaturas médias mensais ocorrentes em Cambará do Sul, região do experimento na FLONA de São Francisco de Paula, RS.

FIGURE 1: Average monthly temperatures and precipitation occurring in Cambará do Sul, region of the experiment at National Forest (FLONA) in São Francisco de Paula, RS.

Ci. Fl., v. 20, n. 3, jul.-set., 2010 
Análise do crescimento em função da precipitação e temperatura

Os resultados do incremento médio mensal das 96 árvores avaliadas por sexo, representados na Figura 3, mostraram que a taxa de crescimento em circunferência do tronco observada nas árvores está diretamente relacionada com a temperatura e precipitação. Foi possível verificar que o aumento da temperatura correspondia ao maior crescimento, cessando-o ou reduzindo-o naqueles períodos com temperaturas mais baixas, ocasiões em que provavelmente ocorria um excesso de água no solo. Os maiores incrementos foram então associados às maiores temperaturas médias mensais e também aos períodos em que houve maior precipitação. Nos meses de inverno, embora tenha existido precipitação abundante, a redução da temperatura pode ter sido o elemento causador da interrupção do crescimento.

Esses elementos meteorológicos afetaram de igual forma árvores masculinas e femininas resultando em crescimentos idênticos para ambos os sexos, em períodos relativamente iguais (Figura 3 e 4). Resultados semelhantes foram encontrados por Ferreira (2002), estudando espécies arbóreas de florestas estacionais em São Paulo onde registrou que os maiores incrementos ocorreram em períodos chuvosos quando comparado com períodos secos, época em que ocorria a diminuição e/ou cessava a atividade cambial.

As mesmas relações descreveram Botosso e Vetter (1991), em estudo com oito espécies da Amazônia, em que num período de 20 meses ocorreu a diminuição ou parada completa da atividade cambial no período de julho a setembro, período esse caracterizado por baixos índices pluviométricos. Idêntica relação, crescimento e precipitação foi descrita por Worbes e Junk (1999) na Venezuela.

Lojan (1965, 1967 e 1968) comparou as variações meteorológicas com a periodicidade do crescimento de espécies florestais de Turrialba, Costa Rica, verificando que as árvores cresciam a cada mês, de acordo com o período de maior precipitação, temperatura e umidade relativa. Da mesma forma, concluiu Cardoso (1991) que a alta precipitação e temperatura foram indicadores do maior índice de atividade cambial em Tectona grandis.

Smith et al. (1997), em estudos realizados com espécies no sul da Bahia, verificaram que apenas a precipitação estava diretamente relacionada com a taxa de crescimento em duas das cinco espécies estudadas. Nas demais, o crescimento foi contínuo durante todo o período de estudo. Segundo esses autores, a falta de sazonalidade da temperatura e ou precipitação em algumas regiões torna difícil

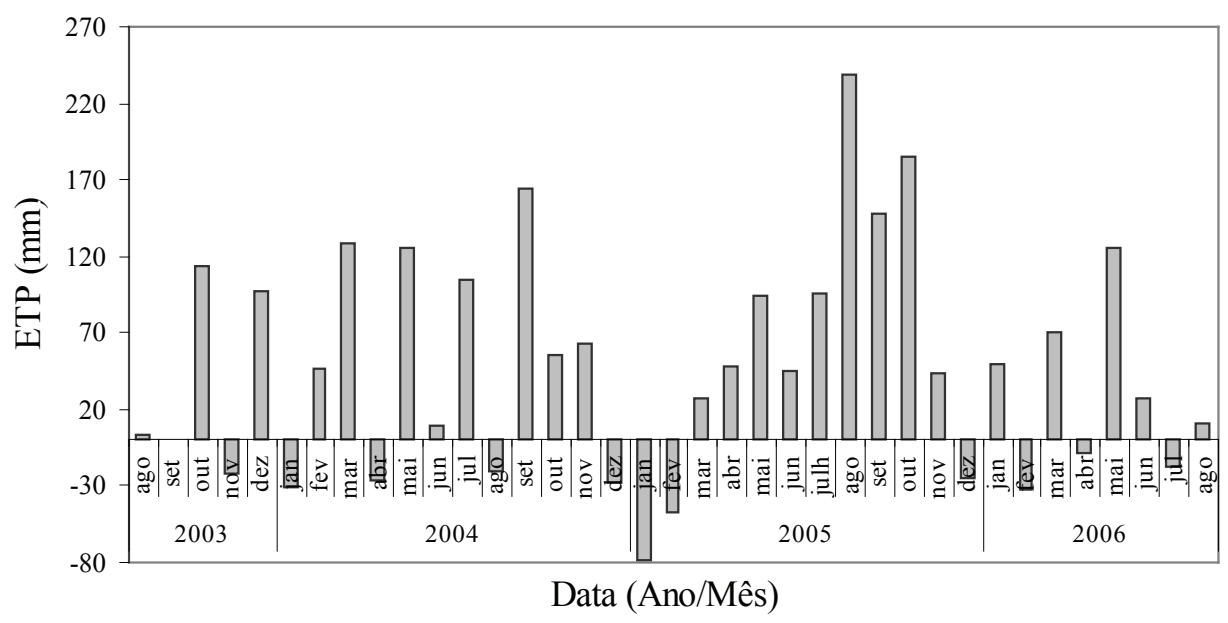

$\square$ Evapotranspiração Potencial - ETP

FIGURA 2: Evapotranspiração potencial ocorrente em Cambará do Sul, região do experimento na FLONA de São Francisco de Paula, RS.

FIGURE 2: Potential evapotranspiration occurring in Cambará do Sul, region of the experiment at National Forest (FLONA) in São Francisco de Paula, RS. 


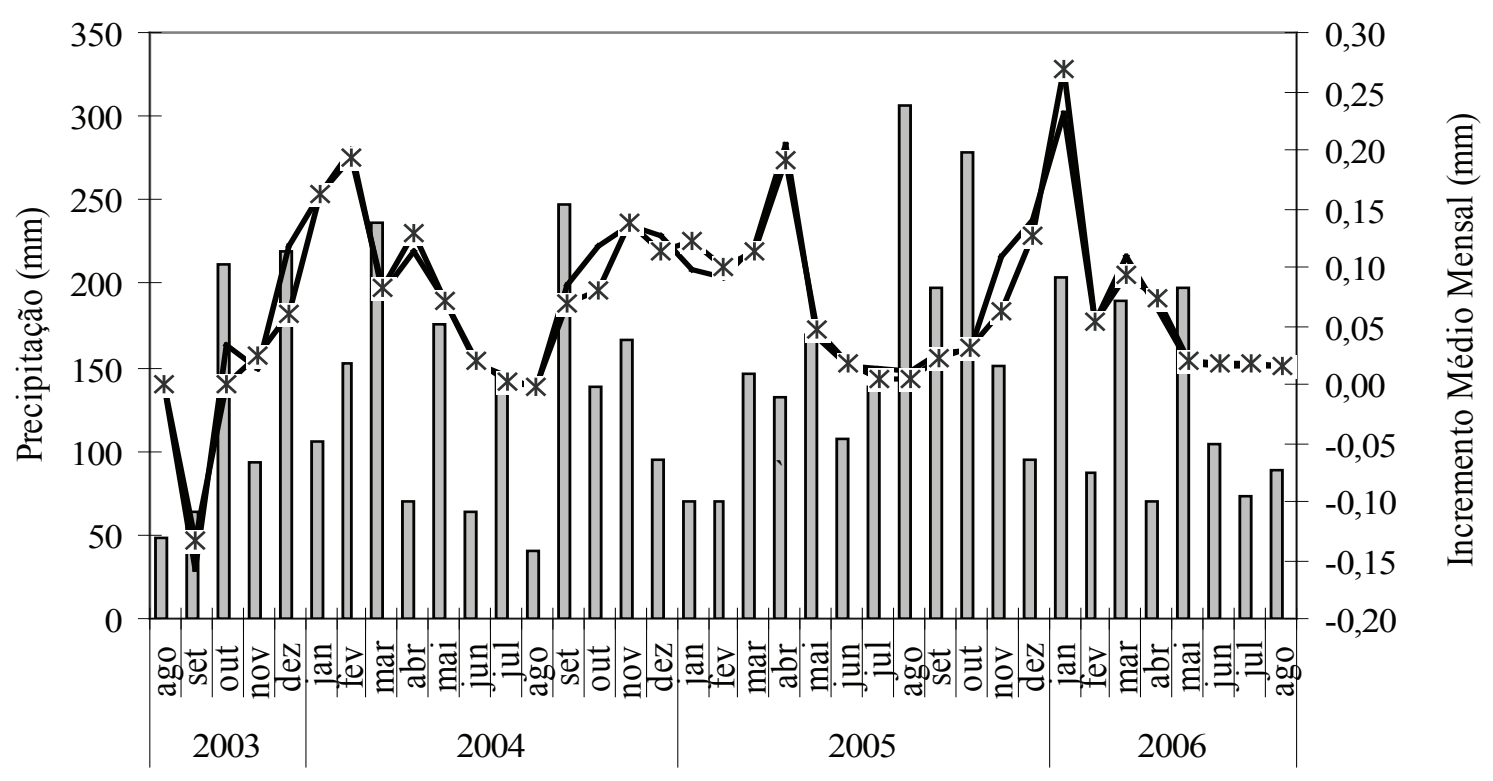

Data (Ano/Mês)

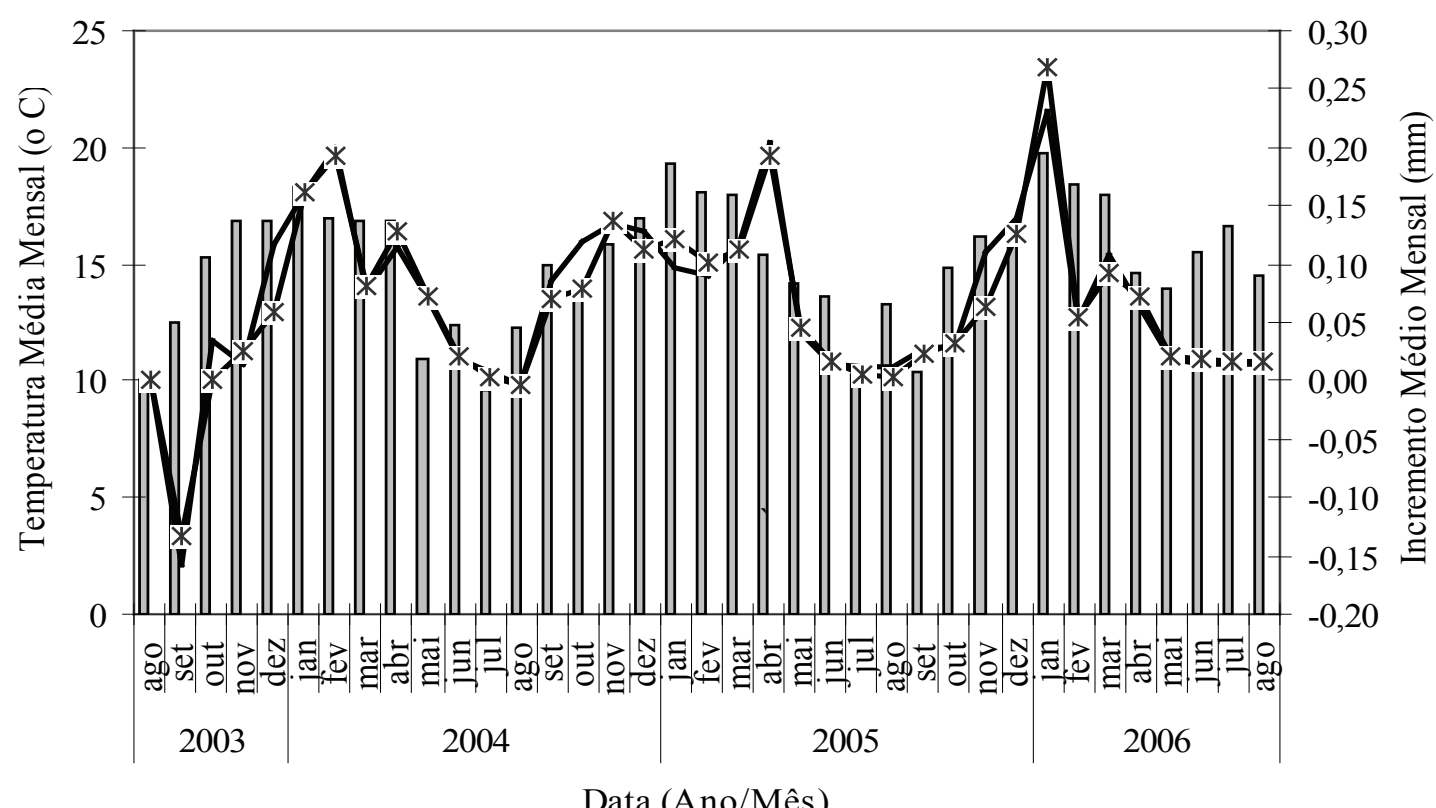

Data (Ano/Mês)

- Feminina $-*-$ Masculina

FIGURA 3: Incremento médio mensal em circunferência à altura do peito (cap), em função das variáveis meteorológicas, temperatura e precipitação para árvores masculinas e femininas de Araucária localizadas na FLONA de São Francisco de Paula, RS.

FIGURE 3: Average monthly increment in circumference at breast-height $(\boldsymbol{c b h})$, in function of meteorological variables, temperature and precipitation, for male and female trees of the Araucaria angustifolia (Bertol.) Kuntze, at National Forest (FLONA) in São Francisco de Paula, RS.

Ci. Fl., v. 20, n. 3, jul.-set., 2010 
determinar a atividade periódica do câmbio vascular.

Nesse estudo, resultados obtidos com a araucária indicaram que a espécie é sensível às oscilações meteorológicas, ou seja, houve mudança na taxa de crescimento relacionada à variação da temperatura e precipitação, porém não houve diferença de crescimento entre os indivíduos masculinos e femininos.
$\mathrm{O}$ crescimento das árvores iniciou a partir do mês de setembro, exceto no primeiro ano de avaliação (2003) no qual foram registrados incrementos negativos nesse período. Esse resultado negativo apresentado nas Figuras 4 e 5 e registrado no gráfico, foi descartado das avaliações e da modelagem, pois representa o período de ajuste das cintas dendrométricas. Nos demais períodos

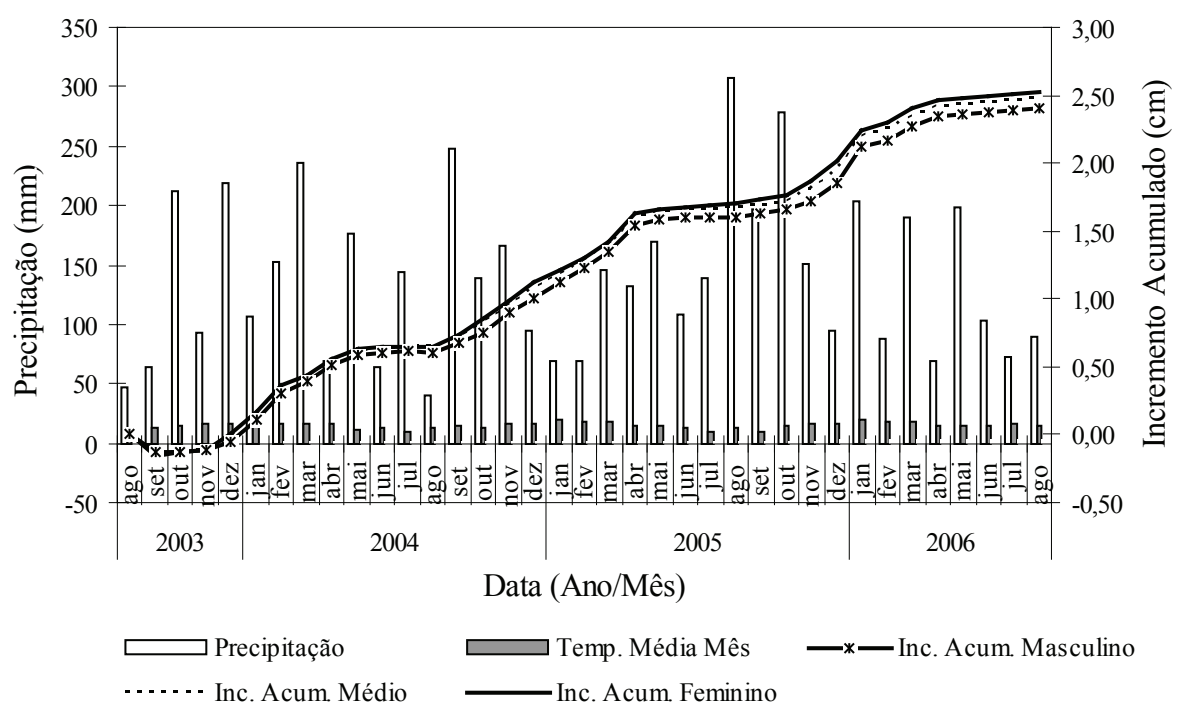

FIGURA 4: Variação do Incremento corrente acumulado em circunferência à altura do peito (cap), para indivíduos femininos, masculinos e sem diferenciação do sexo, localizado na Floresta Nacional (FLONA) de São Francisco de Paula, RS.

FIGURE 4: Variation of the accumulated increment in circumference at breast-height $(c b h)$, for female, male and without distinction of sex, at National Forest (FLONA) in São Francisco de Paula, RS.

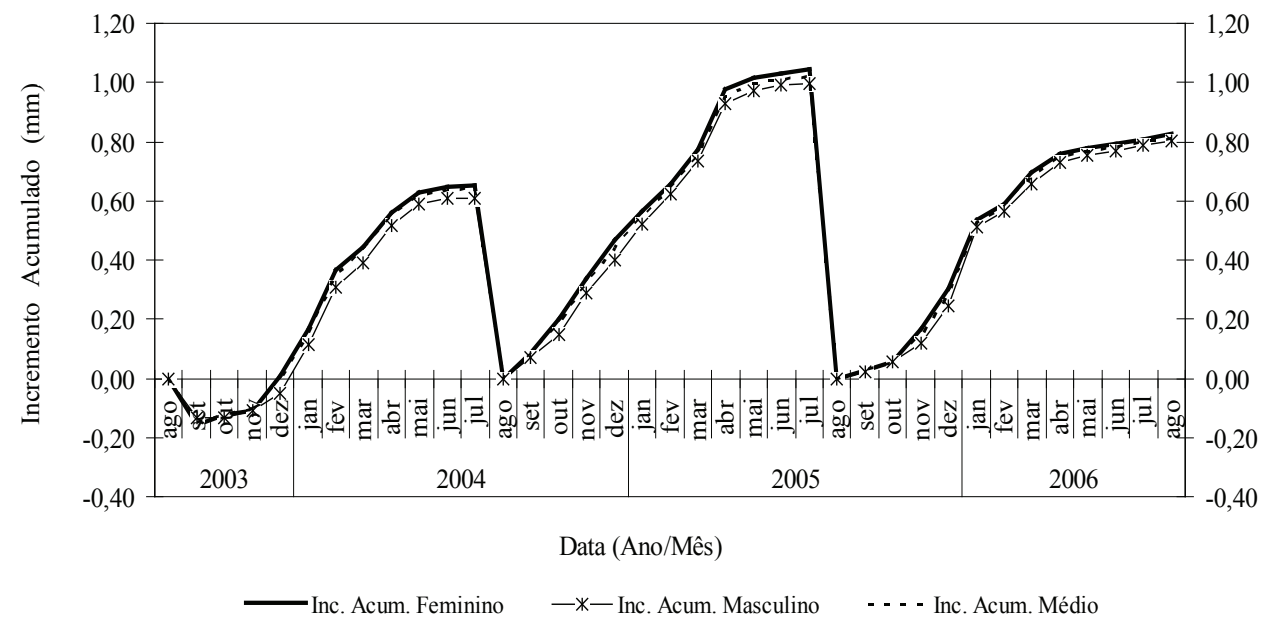

FIGURA 5: Incremento corrente médio anual em circunferência à altura do peito (cap), para árvores femininas, masculinas e sem diferenciação de sexo, localizados na FLONA de São Francisco de Paula, RS.

FIGURE 5: Current annual increment average in circumference at breast-height $(c b h)$, for female, male and without distinction of sex, at National Forest (FLONA) in São Francisco de Paula, RS. 
de avaliação, a atividade cambial começou em setembro e teve seu pico de crescimento nos meses em que não ocorreu déficit hídrico nem temperaturas muito baixas, diminuindo e/ou cessando a atividade cambial a partir de março e abril.

De maneira geral, as árvores cessam ou diminuem a atividade cambial num período que varia de 5 a 6 meses dependendo das variáveis meteorológicas do local, bem como da posição sociológica e vitalidade das árvores. As árvores dominadas apresentaram um menor crescimento em relação às dominantes ou codominantes, mesmo naqueles períodos de temperaturas elevadas. A mesma situação ocorreu nas árvores com classe de vitalidade 1 (copa regular e/ ou alto índice de área folhar verde), em relação àquelas das classes de vitalidade 2 e 3 (copa irregular e/ou baixo índice de área folhar verde).

No primeiro período de avaliação, o pico de crescimento se deu no mês de fevereiro, já no segundo ano, o pico de crescimento ocorreu no mês de abril, decrescendo de maio a julho. No terceiro período, houve um pico de crescimento também em janeiro, com decréscimo em fevereiro, podendo esse fato ser explicado pela baixa precipitação nesse mês. Na fase mais seca algumas árvores reduziram e até paralisaram o crescimento, provocando uma contração da circunferência do tronco, pela perda de água da casca, resultando numa redução dos registros anteriormente tomados nas cintas dendrométricas.

Esse fato foi também relatado por Maria (2002), em estudo da periodicidade de crescimento em que foi verificado que a redução da taxa do incremento ocorria geralmente a partir de março a abril, particularmente para Cedrela fissilis, Copaifera langsdorffii, Centrolibium tomentosum, Tabebuia serratifolia, Balfourodendrum riedelianum e Cariniana estrellensis. Inferindo esses resultados, ao efeito da diminuição e/ou cessação da atividade cambial decorrente do início de déficit hídrico, da precipitação pluviométrica e das temperaturas mais baixas que antecediam o início do inverno.

Worbes (1995) estudou o ritmo de crescimento com o uso de cintas dendrométricas para a espécie Cedrela odorata e observou que esta teve um longo período de dormência cambial durante o período seco; o que não foi observado com a espécie Cordia alliadora, que apresentou um crescimento mais regular.

Fritts (1958 apud KRAMER E KOSLOWSK, 1960) demonstrou que existem variações no crescimento diamétrico durante as 24 horas do dia, produzidas por elementos meteorológicos climáticos, notadamente fatores que influem na hidratação e desidratação da árvore. A importância da chuva foi também registrada por Lojan (1965), descrevendo a correlação positiva do crescimento quinzenal de seis espécies tropicais com a chuva. De acordo com esse autor, nas espécies caducifólias, os períodos de crescimento e repouso não pareceram ser influenciados pela chuva, mas, sim, por fatores internos; já as espécies perenifólias cresceram durante todo o ano, com uma taxa mais reduzida na estação seca.

Com base em estudos de crescimento com algumas espécies tropicais, Détienne (1989) observou que existe uma grande variação no tempo de redução da atividade cambial de algumas árvores, variando de 0,5 a 3 meses, atingindo em algumas espécies 6 a 12 meses. O período de paralisação cambial é função da espécie, das condições meteorológicas e, sobretudo, do vigor das árvores, relacionado à idade e posição sociológica no povoamento.

O incremento médio acumulado das árvores masculinas, femininas e o incremento médio das 96 árvores amostras (FIGURA 5), mostraram que não houve grande diferença entre os valores encontrados para indivíduos masculinos e femininos. Entretanto, a curva de crescimento das fêmeas é levemente superior à observada para os machos, sem, contudo resultar em diferença significativa. Durante o período de amostragem, o maior incremento corrente médio acumulado foi de $6,0 \mathrm{~mm}$ para um exemplar do sexo feminino e $4,88 \mathrm{~mm}$ para o sexo masculino. A média de incremento em diâmetro para o povoamento com 40 anos foi de $2,70 \mathrm{~mm}$ e para o povoamento com 60 anos foi de $2,17 \mathrm{~mm}$.

De maneira geral, apesar da sincronia observada na taxa de crescimento acumulado do diâmetro do tronco houve variação entre alguns indivíduos. Observou-se a existência de árvores que não apresentaram nenhuma taxa de crescimento ou taxa significativamente inferior às demais durante todo o período do estudo.

Reações semelhantes foram observadas por Détienne e Barbier (1988 apud BOTOSSO e VETTER, 1991), que constataram reações muito diferentes em árvores de espécies tropicais na estação seca, com as árvores não obedecendo sistematicamente a um mesmo modelo de crescimento.

$\mathrm{O}$ incremento médio percentual mostrou

Ci. Fl., v. 20, n. 3, jul.-set., 2010 


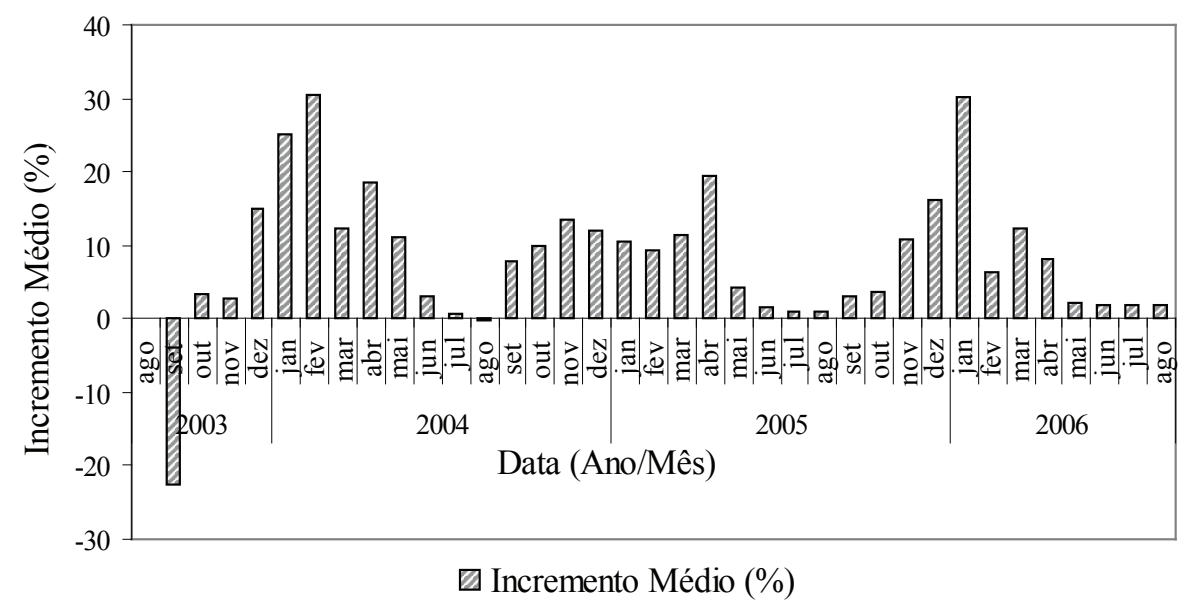

FIGURA 6: Incremento médio percentual nos três anos de avaliação para as 96 árvores localizadas na FLONA de São Francisco de Paula, RS.

FIGURE 6: Average percentage increment in the three year period for the 96 trees, at National Forest (FLONA) in São Francisco de Paula, RS.

que os maiores incrementos (Figura 6) ocorreram em fevereiro para o primeiro período de avaliação e janeiro no terceiro período de avaliação, ambos em torno de $30 \%$. No segundo período de avaliação, o incremento máximo nesse mês foi de $10 \%$, sendo o de maior incremento o mês de abril, com 19,5\%. As maiores taxas percentuais de crescimento foram relacionadas aos meses em que as temperaturas são mais elevadas, independente de ter ocorrido ou não déficit hídrico.

O período de setembro a março mostrou ser responsável por $66,53 \%$ do incremento das árvores ao longo do ano no primeiro período de avaliação, para o segundo ano de avaliação, esse período foi responsável por $74,2 \%$ e no terceiro período, foi de $82,7 \%$. Essa diferença ocorreu, sobretudo, em razão das variações climáticas nos diferentes períodos. $\mathrm{O}$ segundo ano de avaliação teve um período de déficit hídrico maior que os demais, mas isso não refletiu no crescimento geral das árvores nesse período.

\section{CONCLUSÕES}

Com base nos resultados obtidos conclui-se que:

Não há diferença estatística de crescimento entre árvores femininas e masculinas, embora se verifique uma leve tendência das árvores femininas desenvolverem-se um pouco mais.

$\mathrm{O}$ crescimento diamétrico anual das árvores inicia em setembro, tendo seu pico de crescimento no mês de janeiro, decrescendo a partir de março.
O mês de janeiro, é responsável por cerca de $22 \%$ do incremento diamétrico anual das árvores, sendo que, no final desse mês ocorreu em média $57,42 \%$ do incremento anual acumulado das árvores.

Os aumentos das variáveis temperatura e precipitação influem positivamente no incremento. A ocorrência de precipitação acompanhada de temperaturas baixas reduz o crescimento.

\section{REFERÊNCIAS BIBLIOGRÁFICAS}

BACKES, P.; IRGANG, B. Árvores do sul: guia de identificação e reconhecimento ecológico. Porto Alegre: Ed. Pallotti, 2002. 325 p.

BOTOSSO, P. C.; VETTER. R. E. Alguns aspectos sobre a periodicidade e taxa de crescimento em oito espécies arbóreas tropicais de floresta de terra firme (Amazônia). Revista do Instituto Florestal, São Paulo, v. 3, n. 2, p.163-180, 1991.

CARDOSO, N. S. Caracterização da estrutura anatômica da madeira, fenologia e relações com a atividade cambial de árvores de teça (Tectona grandis) - Verbanaceae. 1991. 117 f. Dissertação (Mestrado em Biologia) - Universidade de São Paulo, Piracicaba, 1991.

CLARK, D. A.; CLARK, D. B. Climate-induced annual variation in canopy tree growth in Costa Rican tropical rain forest. Journal of Ecology, v. 82, n. 4, p. 865-872, Dec. 1994.

DÉTIENNE, P. Apperarance and periodicity of growth rings in some tropical woods. IAWA 
Bulletin new series, Leiden, v.10, n. 2, p. 123-132, 1989.

FERREIRA, L. Periodicidade do crescimento e formação da madeira de algumas espécies arbóreas de florestas estacionais semidecíduas da região sudeste do Estado de São Paulo. 2002. 103 f. Dissertação (Mestrado em Ciências Florestais) Universidade de São Paulo, Piracicaba, 2002.

HIGUCHI, N. et. al. Uso de bandas metálicas e dendrômetros automáticos para a definição do padrão de crescimento individual das principais espécies arbóreas da floresta primária da região de Manaus, Amazonas, Brasil. In: PROJETO JACARANDÁ FASE II: Pesquisas Florestais na Amazônia Central, Manaus: INPE, p. 55-68, 2003. HUSCH, B.; MILLER, I. C.; BEERS, T. W. Forest mensuration. New York: John Wiley \& Sons, 1982. $402 \mathrm{p}$.

IBAMA. Floresta Nacional de São Francisco de Paula-RS. Brasília: 2000. 6 p. (Folder).

ISHII, I. H. Estudos dendrocronológicos em matas ciliares do pantanal. In: COLETÂNEA DE SEMINÁRIOS TÉCNCICOS DO CPAPANTANAL, 1996/1997. Corumbá, MS. Embrapa Pantanal. Doc. 23, p. 43-44, Out., 2000.

JACOBY, G. C. Overview of tree-rings analysis in tropical regions. IAWA Bulletin new series, Leiden, v. 10, n.2, p. 99-108. 1989.

KRAMER, P. J.; KOZLOWSKI, T. Fisiologia das árvores. Lisboa: Fundação Caloustre. Gulbenkian, 1960. $745 \mathrm{p}$

LOJAN, L. Aspectos del crescimento diamétrico quincenal del algunos arboles tropicales. Revista Turrialba, v.15, n. 3, p. 231-237, July/Sept. 1965. Periodicidad del clima y del crecimiento de espécies forestales em Turrialba. Costa Rica. Revista Turrialba, v. 17, n. 1, p. 71-83, Enero/Mar, 1967.

Tendências del crescimento radial de 23 especies forestales del tropico. Revista Turrialba, v.18, n. 3, p. 275-281, Jul/Set. 1968.
MARIA, V. R. B. Estudo da periodicidade do crescimento, fenologia e relação com a atividade cambial de espécies arbóreas tropicais de florestas estacionais semidecíduas. 2002. 126 f. Dissertação (Mestrado em Recursos Florestais) - Universidade de São Paulo, Piracicaba, 2002.

MORENO, J. A. Clima do Rio Grande do Sul. Porto Alegre: Secretaria da Agricultura, 1961. 41 p. POORTER, L.; BONGERS, F. Ecology of tropical forests. Wageningen: Agricultural University, 1993. $223 \mathrm{p}$.

SMITH, R. B. et al. Periodicidade do crescimento do tronco em cinco espécies no sul da Bahia. Brasil. Revista Agrotropica. Ilhéus, v. 9, n. 3, p. 99-106, set./dez. 1997.

SPURR, S. H.; BARNES, B. V. Forest ecology. Ronald Press Company, 1973. 571 p.

TEIXEIRA, L L Estudos Dendrocrolológicos de Crataeva tapia. In: COLETÂNEA DE SEMINÁRIOS TÉCNCICOS DO CPAPANTANAL, 1996/1997. Corumbá, MS. Embrapa Pantanal. Doc. 23., p.47-48, Out, 2000.

THORNTHWAITE, C. W.; MATHER, J. R. Instructions and tables for computing potential evapotranspiration and the water balance. Centerton: Drexel Institute of Technology Laboratory of Climatology, 1957. $311 \mathrm{p}$.

VETTER, R. E.; BOTOSSO, P. C. Remarks on age and growth rate determiantion of Amazoniam trees. IAWA Bulletin new series, Leiden, v. 10, n. 2, p. 133-145, 1989.

VILLALBA, R.; WEBLEN, T. T; OGDEN, J. Climatic influences on the growth of subalpine trees in the Colorado front range. Ecology, v. 75, n. 5, p. 1450-1462, July. 1994.

WORBES, M. How to measure growth dynamics in tropical trees: a review. IAWA Journal, Leiden, v. 16, n. 4, p. 337- 351, 1995.

WORBES, M.; JUNK, W. J. How old are tropical trees? The persistence of a myth. IAWA Journal, Leiden, v. 20, n. 3, p. 255-260, 1999. 